\title{
The Pilatus unmanned aircraft system for lower atmospheric research
}

\author{
Gijs de Boer ${ }^{1,2}$, Scott Palo ${ }^{1}$, Brian Argrow ${ }^{1}$, Gabriel LoDolce ${ }^{1}$, James Mack ${ }^{1}$, Ru-Shan Gao ${ }^{2}$, Hagen Telg ${ }^{1}$, \\ Cameron Trussel $^{1}$, Joshua Fromm ${ }^{1}$, Charles N. Long ${ }^{1,2}$, Geoff Bland ${ }^{3}$, James Maslanik ${ }^{1}$, Beat Schmid ${ }^{4}$, and \\ Terry Hock ${ }^{5}$ \\ ${ }^{1}$ University of Colorado, Boulder, Colorado, USA \\ ${ }^{2}$ National Oceanographic and Atmospheric Administration, Earth System Research Laboratory, \\ Boulder, Colorado, USA \\ ${ }^{3}$ National Aeronautics and Space Administration, Wallops Flight Facility, Wallops Island, Virginia, USA \\ ${ }^{4}$ Pacific Northwest National Laboratory, Richland, Washington, USA \\ ${ }^{5}$ National Center for Atmospheric Research, Boulder, Colorado, USA \\ Correspondence to: Gijs de Boer (gijs.deboer@colorado.edu)
}

Received: 13 October 2015 - Published in Atmos. Meas. Tech. Discuss.: 18 November 2015

Revised: 9 February 2016 - Accepted: 27 March 2016 - Published: 28 April 2016

\begin{abstract}
This paper presents details of the University of Colorado (CU) "Pilatus" unmanned research aircraft, assembled to provide measurements of aerosols, radiation and thermodynamics in the lower troposphere. This aircraft has a wingspan of $3.2 \mathrm{~m}$ and a maximum take-off weight of $25 \mathrm{~kg}$, and it is powered by an electric motor to reduce engine exhaust and concerns about carburetor icing. It carries instrumentation to make measurements of broadband up- and downwelling shortwave and longwave radiation, aerosol particle size distribution, atmospheric temperature, relative humidity and pressure and to collect video of flights for subsequent analysis of atmospheric conditions during flight. In order to make the shortwave radiation measurements, care was taken to carefully position a high-quality compact inertial measurement unit (IMU) and characterize the attitude of the aircraft and its orientation to the upward-looking radiation sensor. Using measurements from both of these sensors, a correction is applied to the raw radiometer measurements to correct for aircraft attitude and sensor tilt relative to the sun. The data acquisition system was designed from scratch based on a set of key driving requirements to accommodate the variety of sensors deployed. Initial test flights completed in Colorado provide promising results with measurements from the radiation sensors agreeing with those from a nearby surface site. Additionally, estimates of surface albedo from onboard sensors were consistent with local surface con-
\end{abstract}

ditions, including melting snow and bright runway surface. Aerosol size distributions collected are internally consistent and have previously been shown to agree well with larger, surface-based instrumentation. Finally the atmospheric state measurements evolve as expected, with the near-surface atmosphere warming over time as the day goes on, and the atmospheric relative humidity decreasing with increased temperature. No directional bias on measured temperature, as might be expected due to uneven heating of the sensor housing over the course of a racetrack pattern, was detected. The results from these flights indicate that the CU Pilatus platform is capable of performing research-grade lower tropospheric measurement missions.

\section{Introduction}

The use of unmanned aircraft systems (UAS) for Earth science missions has become increasingly popular over the last two decades. Interest in such deployments stems from the ability of these platforms to collect information on spatial variability of key atmospheric properties and the underlying surface, and provide profiles of atmospheric quantities related to aerosols (e.g., Corrigan et al., 2008; Bates et al., 2013; Platis et al., 2015), clouds (e.g., Ramana et al., 2007), thermodynamics (e.g., Lawrence and Balsley, 2013), turbu- 
lence (e.g., van den Kroonenberg et al., 2012), and radiation (e.g., Ramana et al., 2007; Valero et al., 1996). Additionally, their use has been buoyed by the potential to deploy these aircraft to areas difficult to sample with manned platforms (e.g., Lin, 2006; Elston et al., 2011), including the near surface environment at high latitudes (e.g., Curry et al., 2004; Cassano et al., 2010), and by the potential for significant cost-savings relative to routine deployment of manned aircraft with continued miniaturization of instrumentation and platforms alike.

Programmatic interest in the deployment of UAS developed approximately two decades ago, with the National Aeronautics and Space Administration (NASA), Office of Naval Research (ONR) and US Department of Energy (DOE) establishing UAS-based research programs (Stephens et al., 2000). These programs generally focused on larger, expensive platforms such as the General Atomics Altus and General Atomics Gnat-750. At present, while successful deployments of larger High-Altitude, Long Endurance (HALE) UAS continue (e.g., Jensen et al., 2013; Intrieri et al., 2014), there has been expanded focus on the development and deployment of smaller, low-cost systems. This focus has been fueled in part due to the attainability of such systems for the university research community, as well as by the continued development of regulations by the US Federal Aviation Administration (FAA) and regulating agencies of other countries for small UAS (generally $55 \mathrm{lbs}$ and below). Some examples of such efforts include research flights to investigate lower atmospheric structure in the vicinity of supercell thunderstorms (Elston et al., 2011; Houston et al., 2012), and campaigns to understand lower tropospheric thermodynamics and turbulence (Martin et al., 2011; Reuder et al., 2012; Lawrence and Balsley, 2013).

One area of particular interest for UAS-based research is measurement of atmospheric aerosol particles. At high latitudes, where substantial atmospheric stratification is routinely observed (Persson et al., 2002), and long-range transport of particles is central in establishing the local Arctic aerosol population (e.g., Raatz and Shaw, 1984; Rahn, 1981), measurement of aerosols at the Earth's surface is a critical but insufficient endeavor. In such situations, there is no guaranteed relationship between aerosols observed at the surface and those in the atmosphere above relevant for regulating atmospheric radiative transfer and development of cloud particles. Recent years have seen limited campaigns with manned aircraft (e.g., ISDAC, McFarquhar et al. (2011); ARCPAC, Brock et al. (2011); ARCTAS, Jacob et al., 2010) to better understand the vertical and horizontal variability of aerosol particles. While such campaigns can provide substantial insight and have the unique ability to deploy a variety of instruments to the same location, the cost of such efforts is unsustainable for routine observing. UAS can play a central role in decreasing the cost associated with making aerosol measurements at altitude in the high latitude atmosphere, and to date there have been limited UAS-based measurement campaigns (e.g., Bates et al., 2013; Platis et al., 2015; Altstädter et al., 2015). Of additional interest is the impact of the aerosol and associated cloud particles on the transfer of energy through the Earth's atmosphere. While measurements of irradiance are commonly made at the Earth's surface, such measurements generally only provide the integrated point of view representing the entire column, and do not provide information on specific layers of aerosol or cloud particles and their local radiative impact. Such information can provide critical insight necessary to reduce uncertainty associated with the radiative forcing of aerosol particles and clouds (Anderson et al., 2003). Again, while such measurements have been made using manned aircraft platforms, measurements of atmospheric radiation from UAS have been very limited (e.g., Corrigan et al., 2008; Stephens et al., 2000), and to date have generally focused on downward-looking multispectral cameras to evaluate surface properties.

In this paper, we describe the development and initial testing of the University of Colorado (CU) Research and Engineering Center for Unmanned Vehicles (RECUV) "Pilatus" aircraft. Development of this platform was funded as part of the ERASMUS (Evaluation of Routine Atmospheric Sounding Measurements using Unmanned Systems) campaign, supported by the US Department of Energy (DOE) Atmospheric System Research (ASR) and Atmospheric Radiation Measurement (ARM) programs. Instrumentation for this platform was selected in order to provide critically needed information to understand the vertical stratification of aerosol particles and their radiative impact at high latitudes. At the same time, care was taken to make the best quality measurements possible in order to support ARM's history in providing high-quality data sets. We first provide an overview of the platform, including background on the airframe and flight control systems, followed by details on the instrumentation payload. Subsequent sections provide details on initial results from testing and characterization flights carried out in Colorado, as well as a glimpse into the future deployment of this aircraft to the Arctic environment.

\section{The Pilatus UAS}

\subsection{Airframe and avionics}

The RECUV Pilatus was developed from the airframe of the $3.2 \mathrm{~m}$ Pilatus Turbo Porter almost-ready-to-fly (ARF) kit distributed by Topmodel S.A.S. The Pilatus was chosen for this project due to its established structural integrity, low-speed handling characteristics, and ability to carry significant payloads while still maintaining a total weight of under the $55 \mathrm{lb}$ weight limit established by the Federal Aviation Administration (FAA) for small UAS. This aircraft is also known for its short-takeoff-and-landing (STOL) performance, making it a good candidate for atmospheric research activities where extended runway surfaces are not always available. From a size 
and performance perspective, this aircraft is in a similar class as the ALADINA aircraft developed at the Technische Universität Braunschweig (Altstädter et al., 2015), although the measurement targets of the two systems are somewhat different and the Pilatus is capable of carrying a slightly heavier payload.

Because the primary mission for the ERASMUS campaign involves operation in the Arctic environment, a decision was made to replace the original 8.5 horsepower air cooled, aspirated 2-stroke gasoline engine with an electric propulsion system. This was primarily done due to fears of carburetor icing in the cold Arctic environment. The electric system that was chosen includes a brushless electric motor, powered by a set of four six-cell (22.2 V) 10000 milliAmp hour (mAh) lithium polymer ( $\mathrm{LiPo}$ ) batteries. Unfortunately, this change in the propulsion system does have substantial impact on aircraft endurance, with flight times in the new configuration limited to 25-40 min, depending on payload. With continued development in battery technologies, it seems likely that this endurance will climb steadily in the coming years.

The aircraft is guided by the Piccolo SL autopilot and ground station from Cloud Cap Technology, which is widely used by UAS operators. The ground station's graphical interface communicates with the aircraft via a $900 \mathrm{MHz}$ spreadspectrum data link. This interface allows an operator to control flight parameters of the Pilatus remotely, including setting of speed, altitude and ground track. Waypoints are used to establish the aircraft's course and flight plans can be set ahead of time and can also be modified in-flight. The aircraft is also set up to be flown manually by an operator using a hand-held controller, and flight operations have generally called for manual take-offs and landings while allowing for the Piccolo autopilot to handle the remainder of the established flight pattern.

Additional modifications made to the aircraft include replacement of the landing gear springs in order to handle the impact resulting from increased landing weight. The interior structure of the original aircraft was modified to include a plywood subfloor and the original tires were replaced with larger "tundra tires" for ease of operation from a variety of runway types. In its current configuration, the Pilatus generally cruises at approximately $92 \mathrm{~km} \mathrm{~h}^{-1}$ (50 knots), has a stall speed of approximately $52 \mathrm{~km} \mathrm{~h}^{-1}$ (28 knots), and has a dash speed of approximately $148 \mathrm{~km} \mathrm{~h}^{-1}$ (80 knots). When carrying payload it has a maximum climb rate of approximately $2.5 \mathrm{~m} \mathrm{~s}^{-1}$ and a turn rate of $\sim 30^{\circ} \mathrm{s}^{-1}$, resulting in a $91 \mathrm{~m}$ minimum turn radius.

\subsection{Scientific payload}

To align with the ERASMUS campaign as well as DOE ASR and ARM programmatic scientific and measurement objectives (ASR, 2010), the Pilatus was outfitted with instrumentation that can provide information on atmospheric thermodynamic state (temperature, humidity, pressure), broadband

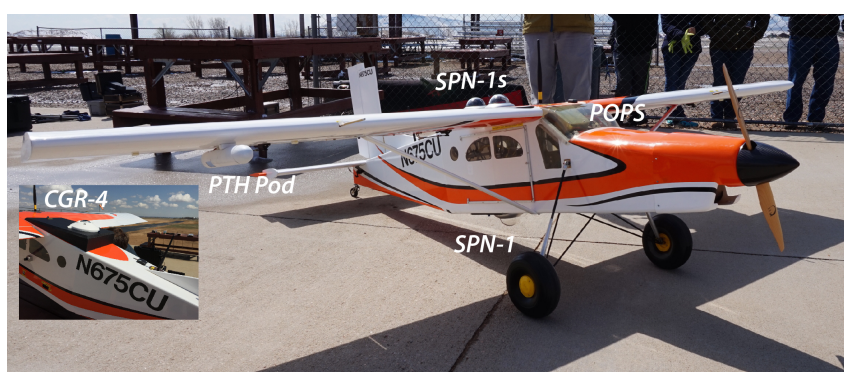

Figure 1. The RECUV Pilatus UAS shown with PTH module (white pod on starboard wing), POPS aerosol spectrometer (gold box in windshield), and three SPN1 pyranometers (two sensors on roof and one sensor on belly). The inset shows the aircraft with the upward-looking CGR4 mounted.

radiation (both shortwave and longwave) and aerosol concentration and size. The following paragraphs provide descriptions of the sensors used on this platform.

\subsubsection{Atmospheric state}

To measure atmospheric thermodynamic state, a specially designed pressure, temperature and humidity (PTH) sensor suite, mounted to the underside of the aircraft wing (Fig. 1) was employed. This PTH sensor module (Vaisala RSS904) is based on the sensor portion of the National Center for Atmospheric Research (NCAR) miniature dropsondes. This module is nearly identical to those used in the Vaisala RS-92 radiosondes used widely in the global radiosonde network in order to derive regular balloon-based thermodynamic profiles, with the exception of the temperature sensor which is larger and more mechanically robust than the RSS904 version. It features a capacitive wire temperature sensor with a $0.1 \mathrm{C}$ resolution, a thin-film capacitor humidity sensor with a resolution of $1 \%$, and a silicon pressure sensor with a measurement resolution of $0.1 \mathrm{hPa}$.

\subsubsection{Broadband radiation}

To measure broadband shortwave $(400-2700 \mathrm{~nm})$ irradiance, the Pilatus was configured to carry three Delta-T Devices Ltd. SPN1 sunshine pyranometers (Fig. 1, top and bottom of aircraft). Of these, both a standard and modified version of this sensor look up towards the sky, and a single modified version looks down towards the ground. The standard SPN1 is unique in that it uses a shading pattern in combination with seven thermopile sensors. This shading pattern ensures that one of the seven sensors is always shaded, meaning that it is only subject to diffuse irradiance from the sun, and that another of the seven sensors is fully exposed to any direct solar radiation. This allows the device to separate the contributions of the incoming shortwave irradiance into cosinecorrected direct and diffuse components, which is critical for correction of the measurement for aircraft motion (see fol- 
lowing paragraph). The modified SPN1s flown remove the shading pattern and have the internal programming changed to output the central detector as one output, and the average of the remaining six surrounding detectors as the other output. In this way, two separate measurements of total shortwave irradiance are obtained. Also important is the fast response time of this sensor $\left(100 \mathrm{~m} \mathrm{~s}^{-1}\right)$. Because the aircraft will potentially be flying around broken clouds, being able to quickly resolve transitions in the measured irradiance is important. The SPN1 is equipped with a heater to prevent condensate formation on the dome. However, in order to reduce power consumption and because we are not planning to operate the aircraft in high-humidity environments, we decided to forgo use of the heater in the Pilatus installation. Without the heaters, the SPN1 requires a power supply of $2 \mathrm{~mA}$ at 5-15 V. Each of these sensors has a $126 \mathrm{~mm}$ diameter and weighs $786 \mathrm{~g}$.

Downwelling shortwave measurements, such as those provided by the SPN1, are very sensitive to aircraft attitude (pitch, roll) due to changes in the orientation of the sensor relative to the sun. Long et al. (2010) provide a technique for correcting for this potential source of error for a combined angular offset from level of up to $10^{\circ}$. In order to follow their approach, it is necessary to be able to distinguish between direct and diffuse contributions to the irradiance, which the SPN1 allows, as discussed above. Additionally, it is necessary to have high-precision information on sensor attitude relative to level. This information was obtained using a VectorNav VN-200 high precision inertial navigation system (INS). The VectorNav combines a three-axis accelerometer, a three-axis gyroscope, a three-axis magnetometer, a barometric pressure sensor and a high-sensitivity GPS receiver in a small and lightweight housing to provide detailed information on aircraft attitude. In order to ensure minimal offset between the position of the VectorNav and the upward-facing SPN1s, the VectorNav was mounted to the bottom of the plate used to mount the SPN1s to the fuselage. Although the standard (with shading pattern) SPN1 allows us to partition between direct and diffuse downwelling total solar irradiance as necessary for correcting for aircraft attitude, the shading pattern used to block half of the sky view increases overall measurement uncertainty. To reduce this uncertainty, we additionally employ a modified (no shading pattern) upwardlooking SPN-1, providing hemispheric total solar measurements. While a similar SPN1 configuration has previously been installed and flown on manned research aircraft (Long et al., 2010), to our knowledge, this is the first application of this sensor to an unmanned research aircraft of any size.

For measuring broadband longwave (4500-42000 nm) irradiance, up- and downward-facing Kipp and Zonen CGR4 pyrgeometers were integrated into the aircraft system. The CGR4 is among the best pyrgeometers available commercially and is among those used in the World Meteorological Organization (WMO)'s Baseline Surface Radiation Network (BSRN). The CGR4 uses a silicon meniscus dome which provides a $180^{\circ}$ field of view. Additionally, the design of the CGR4 reduces dome heating due to absorption of solar radiation to a negligible level when ventilated eliminating the need for dome temperature measurements or dome shading. Because the CGR4 has a very low output signal $(-1.5$ to $0 \mathrm{mV}$ ), the instrument is paired with a Kipp and Zonen AMPBOX amplifier in order to convert this into a more reliably readable 4-20 mA current loop signal. Each CGR4, with the shading dome, has an exterior diameter of $150 \mathrm{~mm}$, and a weight of $600 \mathrm{~g}$.

\subsubsection{Aerosol size distribution}

To characterize aerosol size distribution, the Printed Optical Particle Spectrometer (POPS, Gao et al., 2016) designed, engineered and constructed at the National Oceanographic and Atmospheric Administration (NOAA) Earth System Research Laboratory (ESRL) Chemical Sciences Division (CSD), was integrated into the aircraft. This lightweight, low-cost sensor is constructed using 3-D printing technology and provides aerosol concentrations and particle size distributions for particles between 140 and $3000 \mathrm{~nm}$. Particles are sized on an individual basis to provide a continuous size distribution. A compact data system features a custom electronic design including a single board computer. The sensor and electronics consume $7 \mathrm{~W}$ of power at $9-15 \mathrm{~V}$, allowing for extended operation on a relatively small battery system. POPS components combine for a total weight of approximately $800 \mathrm{~g}$. The inlet for POPS is located on the wing in an isoaxial configuration, but the flow is not isokinetic, as POPS draws air at a rate of $3 \mathrm{~cm}^{3} \mathrm{~s}^{-1}$ using a small pump. The tubing between the inlet and the sensor is constructed mainly of stainless steel tubing with some smaller section of conductive silicone. The tubing has an inner diameter of $0.00159 \mathrm{~mm}$ (1/16 inch), with an overall length of $1.65 \mathrm{~m}$. The inlet tubing does have four bends, three of which are approximately $90^{\circ}$, and one is approximately $180^{\circ}$. The large difference between the aircraft cruise speed and inlet airspeed results in some oversampling of larger particles as shown by Fig. 4, based on Baron and Willeke (2001).

\subsubsection{Data acquisition and video camera}

To command and collect information from the various payload components, a custom command and data handling/signal conditioning (C\&DH) board was designed. This board consists of various components, including a main board borrowed from the autopilot of the DataHawk UAS (Lawrence and Balsley, 2013) consisting of a microcontroller with support components and a Micro-SD card for data storage. Additionally, the C\&DH board includes an IMU with a three-axis gyroscope, a three-axis accelerometer, a three-axis magnetometer and a barometric pressure sensor, an XBee $900 \mathrm{MHz}$ radio for real-time telemetry, and signal conditioning circuitry for the analog components. With this configu- 
Table 1. An overview of the three different Pilatus payload configurations.

\begin{tabular}{llr}
\hline Name & Instruments & $\begin{array}{r}\text { Payload } \\
\text { weight }\end{array}$ \\
\hline Core & PTH, Camera, POPS & $2 \mathrm{~kg}$ \\
Shortwave & Core, plus SPN1s, VectorNav & $4.3 \mathrm{~kg}$ \\
Longwave & Core, plus CGR-4s & $3.3 \mathrm{~kg}$ \\
\hline
\end{tabular}

ration, there were some key design requirements, including achieving the highest precision and accuracy possible from the CGR4s and SPN1s, integration of a high-quality attitude measurement from the VectorNav VN-200 IMU, and efficient routing of power from the three-cell lithium polymer payload battery, which is separate from the larger propulsion and avionics batteries. Software was designed to provide two forms of payload telemetry. The primary mode of telemetry is a $\log$ file generated and stored on the onboard Micro SD card. Main payload packets are generated at $25 \mathrm{~Hz}$, though individual instruments may not report at this frequency. In addition to the main data packet, a $5 \mathrm{~Hz}$ GPS packet is also generated. In addition to the SD card logging, a $1 \mathrm{~Hz}$ realtime telemetry stream is generated via the XBee radio, containing only PTH data in ASCII text format.

A central design requirement for the C\&DH board was minimization of electronic noise on the analog sensor (SPN1 and CGR4) outputs. As discussed above, we integrated a Kipp and Zonen AMPBOX with the CGR4s. In order to minimize the potential for noise pickup and generation, this AMPBOX was mounted directly on the bottom of the CGR4 housing to minimize the length of the cable carrying the lowvoltage signal from the sensor to the amplifier. In general, all voltages were amplified as early as possible in order to match the range of the analog-to-digital converter. Additionally, the data system is powered by a dedicated battery in order to separate the electronics from those associated with the avionics and motor, and we used linear power supply regulators and decoupling capacitors on all circuit power lines. The circuit board and cables were designed using best practices, separating analog and digital circuits to minimize noise coupling. Finally, all cables used were shielded and extra care was taken to avoid ground loops. With this, the estimated electronic noise levels for the analog sensors used are $0.15^{\circ}$ for the CGR4 temperature reading, $3 \mathrm{~W} \mathrm{~m}^{-2}$ for CGR4 irradiance, and $1.5 \mathrm{~W} \mathrm{~m}^{-2}$ for SPN1 irradiance.

Finally, in order to document the flight environment a FatShark PilotHD V2 video camera capable of recording $720 p$ video at 30 frames per second (fps) to an integrated SD card logger. This camera is equipped with a $1 / 2.5$ inch 5 megapixel imager and features a metal-cased shell for protection and minimization of radio frequency interference with aircraft controls. The weight of the camera system is approximately $33 \mathrm{~g}$.

\subsubsection{Payload configurations}

Unfortunately, due to the weight of the radiation instrumentation, not all of the instruments listed above can fly simultaneously. Therefore, we have configured our data logging and electronics systems and the distribution of sensors on the aircraft in order to allow for easy swapping of three payload configurations (Table 1). The first configuration includes POPS and the PTH module only and allows for the use of two extra $10000 \mathrm{mAh}$ propulsion system batteries, extending flight duration to approximately $40 \mathrm{~min}$ with a combined instrument payload mass of approximately $2 \mathrm{~kg}$. This configuration is ideal if an extended range of operation is desired, or if aerosol profiles to higher altitudes $(>750 \mathrm{~m})$ are desired. The second configuration carries the PTH module and POPS, as well as upward and downward looking CGR-4s with a combined instrument payload mass of approximately $3.3 \mathrm{~kg}$. Using this configuration, flight time is restricted to approximately $25 \mathrm{~min}$, depending on the mission flown. The third, and heaviest configuration includes the PTH module and POPS in combination with the three SPN1s and the VectorNav INS, resulting in a combined instrument payload mass of $4.3 \mathrm{~kg}$. In order to make the instrument swaps as easy as possible, the CGR4 and SPN1 instruments were fixed to separate mounting plates which had uniform mounting points for attachments to the airframe. To ensure that the upwardlooking radiometric instrumentation is as level as possible during flight, the roof-mounted plate is placed upon a shim which angles those instruments at approximately eight degrees relative to the roofline (see Fig. 1 inset) in order to set them as close to level as possible during flight.

\section{Characterization of IMU offset}

Options for operation of unmanned aircraft in US airspace for government operators, including the university research community, are limited. Testing and evaluation of Pilatus equipment was completed under COA 2013-WSA-26, allowing for operation of the Pilatus by University of Colorado operators at the Arvada (Colorado, USA) Field at or below $122 \mathrm{~m}$ (400 ft) above ground level. In order to correct the measured SPN1 values for orientation as outlined in Long et al. (2010), it is necessary to determine the angular offsets between what is deemed to be level by the VectorNav IMU and the actual level state of SPN1 detectors. While the two are mounted to a common plate, small differences in the mounting or manufacture of the sensors can result in an offset in level states. To characterize this, it is necessary to collect a data set containing various permutations of pitch, roll, and heading plus changes in latitude and longitude. Because the VectorNav has to be moving to get accurate measurements of heading, it is necessary to complete the characterization of it's orientation offset relative to the SPN-1s using a moving platform. However, the limited spatial domain available 

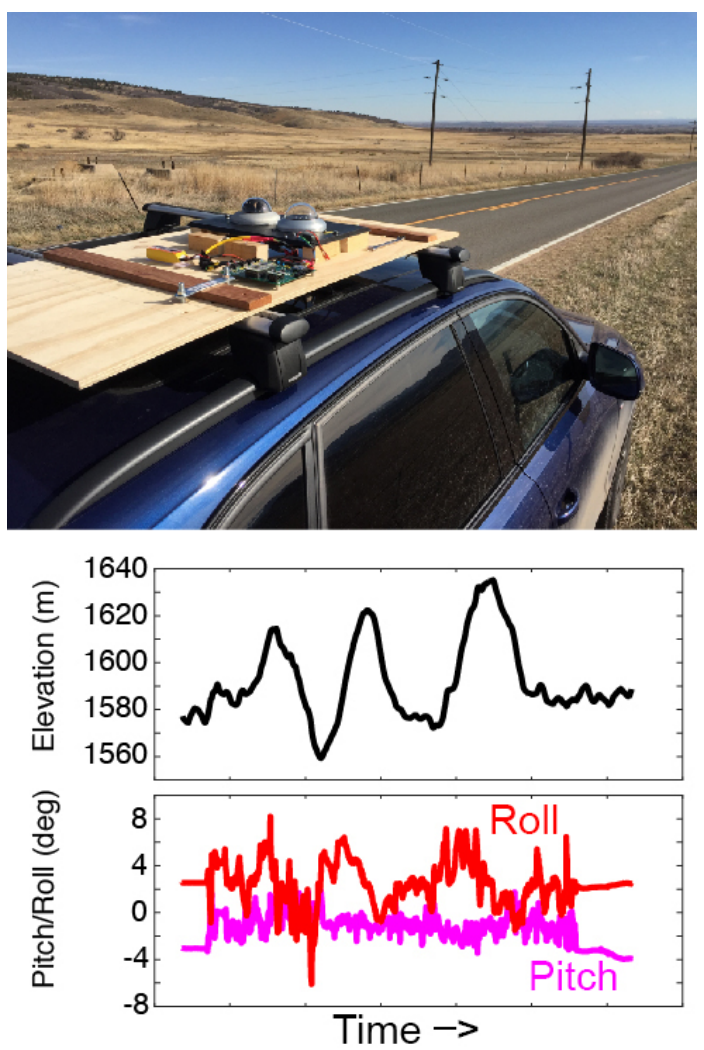

Figure 2. The SPN1 configuration mounted on top of a team member's vehicle for obtaining measurements required to calculate the relative offset between the VectorNav and upward-looking SPN1s (top). The elevation variability of the route driven for offset characterization purposes (black line), compared with pitch (magenta) and roll (red) measured during one transit of this route. The instrumentation was turned $90^{\circ}$ (yaw) between laps in order to ensure that the hill structure provided adequate variation in both pitch and roll for offset characterization.

for flight under the COA is not supportive of the execution of extended legs with nearly "level" (limited pitch and roll) flight, as would be preferable for radiation measurements and offset characterization. Therefore, we instead implemented a car-based solution for characterization of the VectorNavSPN1 offset with a roof-mounted system (Fig. 2, top).

In order to obtain the measurements required to characterize the offset between the VectorNav and the SPN1 sensors, it is required to vary the orientation of this platform over a range of pitch and roll angles under a variety of solar zenith angles. Using this ground-based approach, this requires the execution of a series of rectangular patterns driven on a cloud-free day over terrain with rolling hills from sunrise until around solar noon (Fig. 2, middle, bottom). To ensure variability in both pitch and roll, the sensor plate was turned $90^{\circ}$ in orientation (yaw) between each executed run. In total, 14 circuits were completed on public roads in northwestern Boulder, Colorado, between 07:20 and 12:20 local time, with approximately $20 \mathrm{~min}$ in between the start of each circuit.

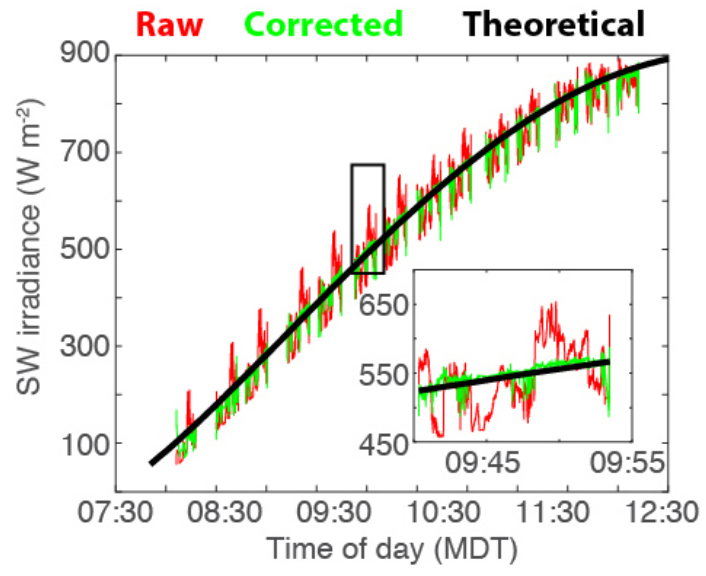

Figure 3. Downwelling broadband shortwave irradiance $\left(\mathrm{W} \mathrm{m}^{-2}\right)$ obtained using the car-top mounted SPN1s during offset characterization runs. The red line represents the uncorrected values, while the green line represents the measurement after attitude correction has been applied. The black line represents the theoretical clearsky value for the time and location of the measurements. The inset shows the corrected and uncorrected values for one loop around the circuit (shown by black box).

Using the results from these patterns, we applied the technique outlined in Long et al. (2010) to characterize the offset between the VectorNav and the SPN1s and to allow for the correction of SPN1 measurements for deviations from level of up to $10^{\circ}$. These offsets were found to be very small ( 0.4 , 0.4 , and $2.4^{\circ}$, for pitch, roll, and yaw, respectively), which is not surprising considering the VectorNav and SPN1s are co-mounted on a single plate.

Figure 3 shows the raw (red) and corrected (green) downwelling broadband shortwave irradiance measurements from the car-top SPN1 runs. The raw measurements show the effect of small pitch and roll variations on the measured irradiance, with spikes in the data of up to nearly $100 \mathrm{~W} \mathrm{~m}^{-2}$ for tilt from horizontal of only up to $7^{\circ}$. After the correction is applied, these are efficiently corrected, providing an accurate representation of the clear-sky irradiance at this time. The reductions in the measured irradiance visible in both the raw and corrected data are the result of shadows from trees and structures along the route of travel. The gradual increase of the measured irradiance with time is the result of the increasing elevation of the sun in the sky moving from early morning to the middle of the day.

\section{Flight testing and airborne data}

In-flight testing of the aircraft and integrated instrumentation was completed at Arvada Field under the COA mentioned above during February-April 2015. Here, we provide an overview of results from a series of instrumented preparation flights completed on 3 April 2015. These flights were 
completed between 11:30 and 15:00 local time, under partly cloudy conditions and relatively light winds. Synoptically, a weak area of low pressure moved through the Front Range of Colorado on the evening of April 2nd, resulting in a few inches of snowfall. This snow was covering much of the ground surface early on, but by the time the first flight began, the runway was already clear of snow, and the snow cover on the surrounding fields was spotty. The snow would continue to melt throughout the day, as broken clouds and sun resulted in fairly rapid heating of the lower atmosphere. In total, four flights were carried out at an altitude of $100 \mathrm{~m}$, with the aircraft executing a counterclockwise racetrack pattern under autopilot guidance. These flights ranged from 20 to nearly $24 \mathrm{~min}$ in duration. The first and fourth flights carried the "shortwave" payload (see Table 1), while the second and third flights carried the "longwave" payload.

Thermodynamic profiles from the four flights are presented in Fig. 5. It is important to note that these flight patterns were not set up specifically for profiling, and therefore the ascent and descent rates were not uniform through the depth of the column. The profiles presented represent binned distributions covering both the ascending and descending portions of flight. Figure 5 (top) shows potential temperature profiles, which depict a lower-atmospheric column that is slowly warming up as a result of solar heating of the surface. These profiles represent binned distributions at $5 \mathrm{~m}$ resolution, with the mean at each height illustrated by the filled circles. The thin lines represent the interquartile range at each altitude, providing insight into the variability at a height. It should be noted that very little time was spent at intermediate altitudes, and the majority of each flight was conducted at the cruise altitude (near $90-100 \mathrm{~m}$ in flights 1 and 3 and 80 $90 \mathrm{~m}$ in flights 2 and 4). This, in combination with some lag inherent to the sensor response time results in values over the lowest portion of the atmosphere that appear superadiabatic. The rapid transit through the area closest to the surface is also the primary driver for the apparent increase in variability (larger IQR spread) at lower altitudes. Beginning at around $40 \mathrm{~m}$, the profiles represent a well-mixed atmosphere, as may be expected on a relatively sunny and warm day with some wind. Since relative humidity is a function of temperature, over a short amount of time and without significant advection of water vapor, increasing temperatures resulting from solar radiation will tend to decrease relative humidity values. Profiles of relative humidity from the PTH module (Fig. 5, middle) appear to illustrate this phenomenon, with relative humidity values decreasing throughout the day as boundarylayer temperatures increase. There does appear to be a thin layer of elevated moisture levels near the surface, potentially the result of melting snow and the associated evaporation of surface water into the relatively dry atmosphere. Atmospheric pressure drops slightly during the third and fourth flights, with pressures from the first two flights being nearly identical (Fig. 5, bottom).

\section{Total Aspiration Sedimentation Bends}

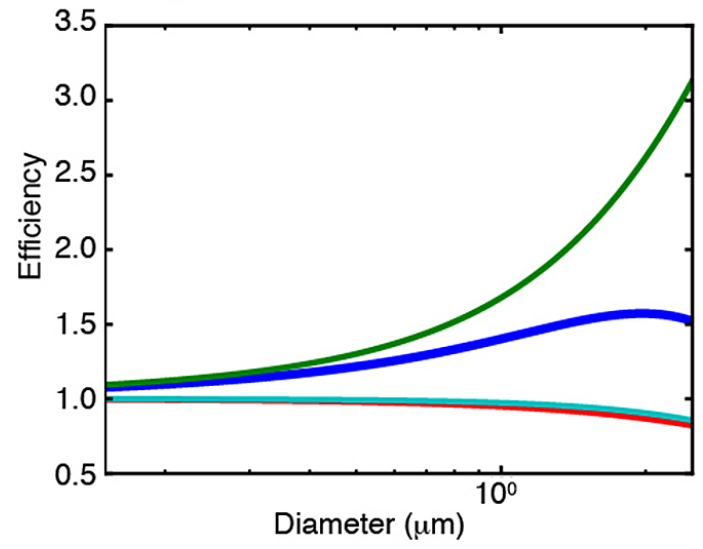

Figure 4. Sampling efficiency of POPS on the Pilatus.

One question that we attempt to answer with the test data collected is whether sensor orientation influences the temperature observed with the PTH module mounted on the wing. Figure 6 provides distributions of the difference between the measured temperature above $60 \mathrm{~m}$ in altitude (GPS) and the mean temperature at this elevation, binned by aircraft heading. The distributions include a mean value (symbol), the interquartile range (thick line) and the 10th-90th percentiles (thin lines), with positive values indicating that measurements from that heading were warmer than the mean. The yellow bars represent the range in solar azimuth angles covered during that specific flight to provide information on how the sensor is oriented with respect to the sun. With the sensor mounted on the starboard wing, this results in the shading of the nose of the sensor housing when the aircraft is flying away from the sun and across the sun towards the west. While both flights 3 and 4 appear to demonstrate warming when the starboard wing is oriented toward the sun (directions less than the solar azimuth angle), such warming is less apparent in the first two flights. There does not appear to be a systematic bias based on heading relative to the sun from these flights, with the caveat that the aircraft is only maintaining any given heading for a maximum of 20-30 s at a time. This seems to support design of the PTH sensor housing to both reduce direct airflow (and thereby convective cooling) as well as direct heating through absorption of solar radiation.

In addition to the PTH data, we also present measurements from flights completed with the Kipp and Zonen CGR4 (broadband longwave) and Delta-T SPN1 (broadband shortwave) sensors. As mentioned above, the flights 1 and 4 were completed with the SPN1s, while flights 2 and 3 were completed with the CGR4s installed. In general, the scene for these flights is rather complex from a radiation perspective. The surface included both dark (earth) and bright (snow) covered areas, and the sky featured broken fair-weather cumulus clouds. To add to the complexity, there is some terrain around 

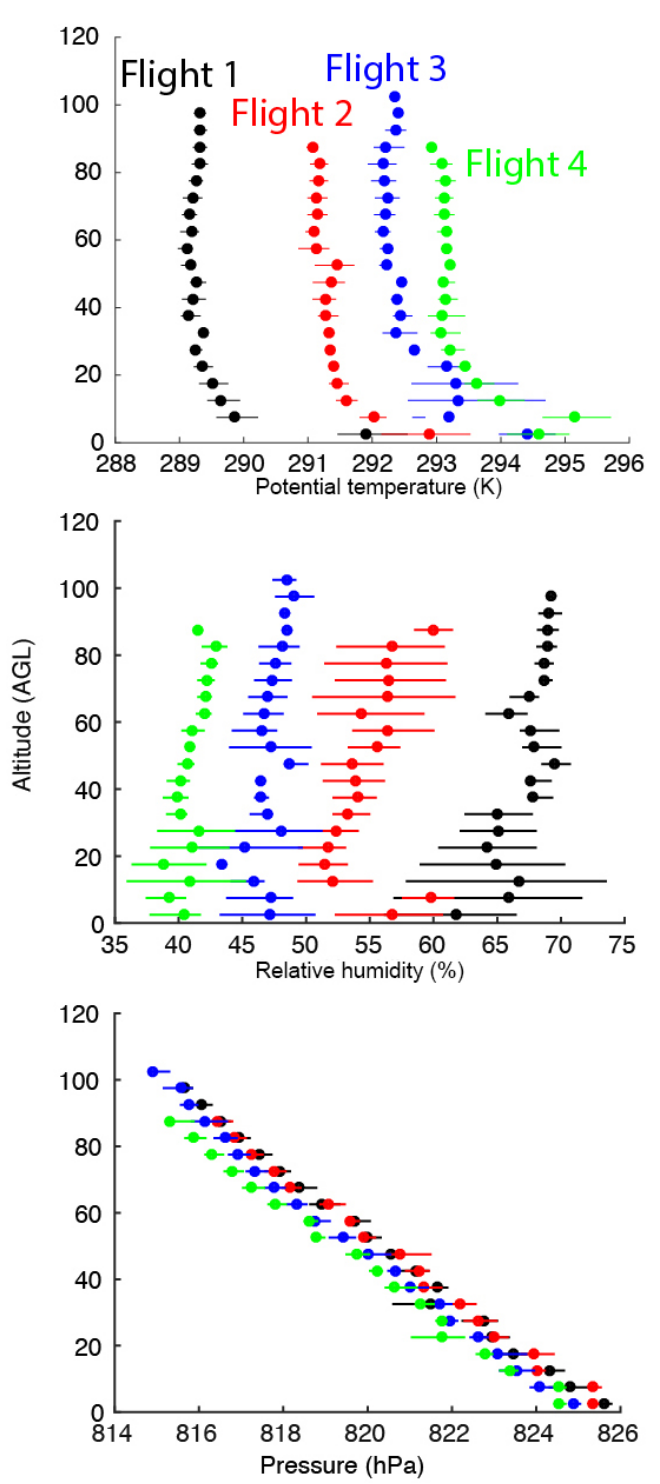

Figure 5. Potential temperature (top), relative humidity (middle) and atmospheric pressure (bottom) from the four 3 April flights. The circles represent the mean value at each altitude, while the lines represent the inter-quartile range.

the flight test site that can enter the field of view of the sensors, and substantial terrain (front range of the Rocky Mountains) approximately 10-20 miles away. Given the limited amount of area available for flight, we were also required to fly a relatively tight racetrack pattern, resulting in a substantial fraction of non-level (i.e., high pitch/roll angles) flight.

As visible in Figs. 7 and 8, the factors discussed in the previous paragraph result in substantial variability in both the short- and longwave radiation measured during these flights. Both data sets show regular periodic variability as a result of aircraft motion. While the downwelling shortwave signal is corrected for tilt effects, the complex cloud cover scene and surrounding terrain result in real variability with tilt that

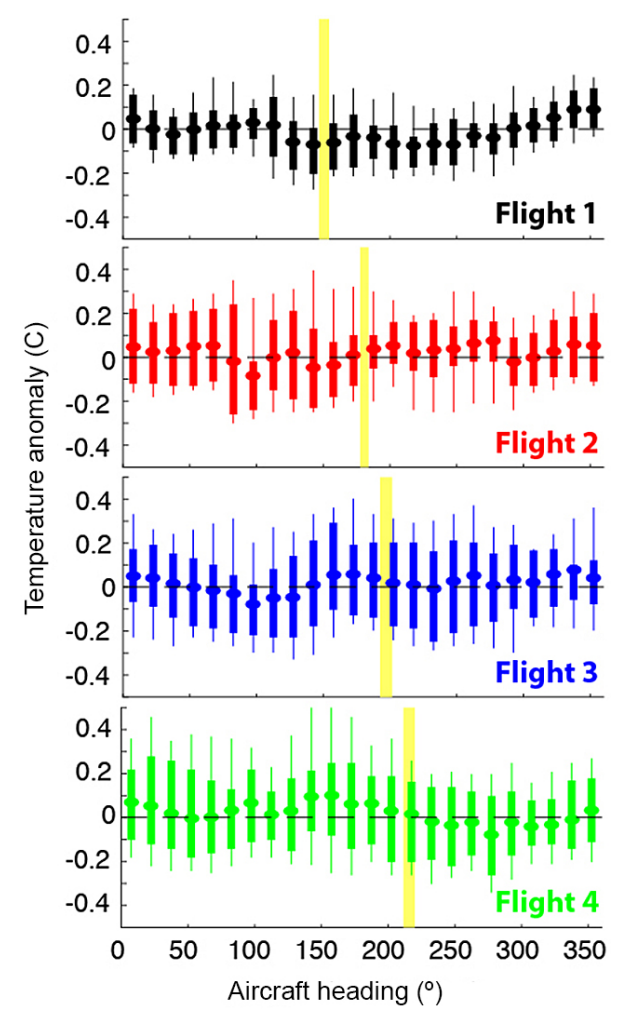

Figure 6. Distributions of temperature anomalies from the mean of all points above $60 \mathrm{~m}$ for each flight as a function of aircraft heading. The mean of the distribution is presented as a closed circle, the interquartile range is presented as the thick line, and the 10th-90th percentile range is presented as the thin line. The yellow bars represent the range of solar azimuth angles for each flight.

is not directly connected to the solar position relative to the sensor.

Looking first at the longwave irradiance (Fig. 7), variability in the signal is largely the result of the wide field of view of the sensor. While this wide field of view is desirable for surface-based operations in order to ensure that contributions from the entire hemispheric atmosphere are represented, unfortunately for aircraft-based operations, each change in flight heading results in an instrument reading from a non-level configuration, which results in measurements that represent a combination of sky and surface radiation. The limited flight area, in combination with the relatively slow response time of the CGR-4 (18 s at $95 \%$ response, $6 \mathrm{~s}$ at $63 \%$ response), results in a periodic oscillation in both the down- and upwelling longwave radiation measured during these flights. In order to gain insight into the accuracy of the aircraft-based measurement, we compare the Pilatus measurements to $1 \mathrm{~min}$ averaged irradiances obtained at the $\mathrm{Na}$ tional Renewable Energy Laboratory (NREL) "South Table Mountain" radiometer facility in Golden, Colorado. This site is approximately $12 \mathrm{~km}$ from the Arvada airfield where the flights took place, and therefore the values are not expected 


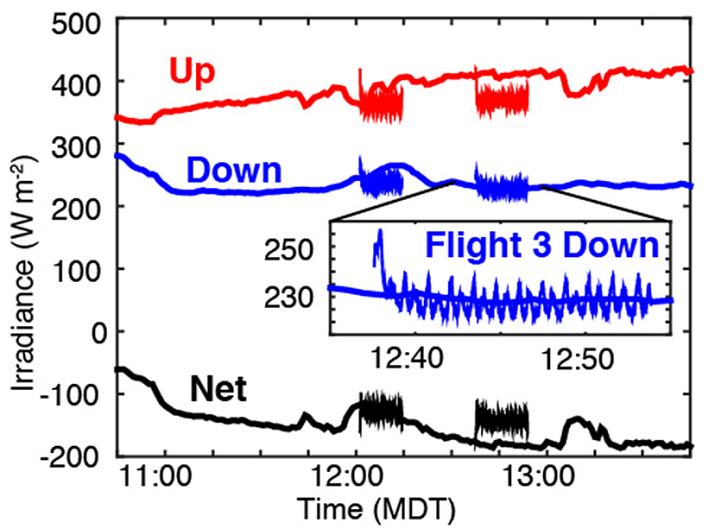

Figure 7. Broadband longwave radiation measured during the time of testing on 3 April 2015. Included are upwelling (red), downwelling (blue) and net (black) radiation from the aircraft (thin, shorter line segments with high variability) and $1 \mathrm{~min}$ averages from the NREL site at Table Mountain (thicker lines). An inset is included to provide additional detail on the downwelling radiation measured from the aircraft and at Table Mountain for the third Pilatus flight of the day.

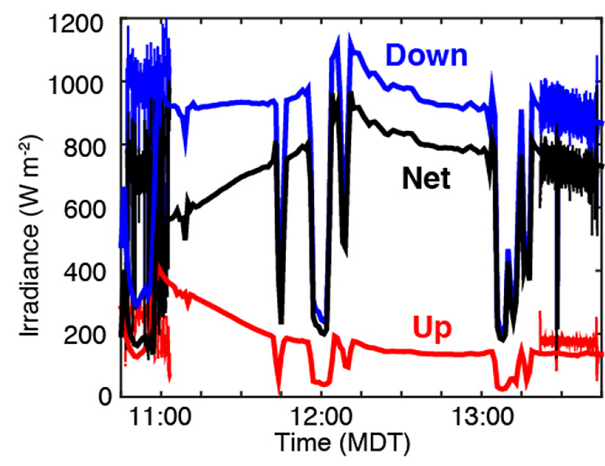

Figure 8. Broadband shortwave radiation measured during the time of testing on 3 April 2015. Included are upwelling (red), downwelling (blue) and net (black) radiation from the first and fourth aircraft flights (thin, shorter line segments with high variability from approximately 10:45 to 11:02 and 13:20 to 13:44 MDT) and $1 \mathrm{~min}$ averages from the NREL site at Table Mountain (thicker lines).

to compare exactly. From a general comparison, however, the aircraft-based measurements appear to agree reasonably with the surface-based measurements. The largest difference appears to be that the surface at Table Mountain appears to be warming faster than at Arvada, resulting in a larger difference between the two measurements during the second flight. Interestingly, the Pilatus-measured downwelling measurement appears to agree very well with the Table Mountain measurement, once the aircraft is at altitude.

The tilt-corrected broadband shortwave irradiance measured by the SPN1s are illustrated in Fig. 8. The corrections applied for this specific set of flights are illustrated in Fig. 9 as a function of aircraft heading and total (two- dimensional) tilt angle. The top panel of this figure illustrates the general tendency of positive tilt angles (towards the sun) to have higher irradiance values, and negative tilt angles to have lower irradiance values. The calculated corrections are illustrated in the central panel, with corrections limited to a maximum tilt magnitude of $10^{\circ}$. Finally, the tilt-corrected irradiance is shown in the bottom panel of the figure.

Looking at the corrected values (Fig. 8), the blue color represents downwelling irradiance from the aircraft (thin line) and the NREL Table Mountain Kipp and Zonen CMP22 pyranometer (thick line). The large drops visible in the NREL data set during this time represents the passage of clouds over the sensor. The Pilatus SPN1 measurements agree very well with the CMP22 measurement for both flights, although data from flight 1 happened to coincide with the overpass of one of these clouds over the Table Mountain site. The red lines indicate the upwelling values measured using the downward looking SPN1 on the Pilatus (thin line) and a downward looking Kipp and Zonen CM3 at the Table Mountain site (thick line). At the time of flight 1 , the upwelling shortwave measured by the CM3 is substantially higher than that measured by the aircraft. Because this time period featured a rapidly melting snow layer on the surface, this difference is likely the result of a more uniform or thicker snow surface at the Table Mountain site. By the time that flight 4 occurred, the difference between the two sensors and locations has decreased dramatically, with the Pilatus SPN1 measurement actually being slightly higher than the Table Mountain CM3. Again, this is likely due to differences in the surface state and type at the location of the measurement. The black lines represent the net broadband shortwave irradiance, calculated as the difference between the measured downwelling and upwelling irradiance.

One of the unique aspects of the SPN1 instrument is that it provides a direct measurement to distinguish between direct and diffuse contributions to the measured irradiance. The values for flight 1 and flight 4 are shown in Fig. 10, with the light blue line representing the measured (uncorrected) total irradiance, the dark blue line representing the corrected total irradiance, the black line representing the direct component of the measured signal and the grey line representing the diffuse component of the signal. From this, we can see some subtle differences between these two flights. For example, flight 1 has substantially greater variability in the net irradiance, with several instances where the direct component drops to zero. This is the result of a substantial coverage of broken cumulus clouds, which, at times completely shielded the SPN1 from direct sunlight. These clouds had mostly dissipated later in the day, resulting in a more consistent total irradiance and ratio of direct to diffuse irradiance. We also note that the diffuse contribution has decreased between flight 1 and flight 4 , which results from a combination of lower sun angles during flight 4 , less cloud cover, and a generally drying atmosphere (see Fig. 5). 


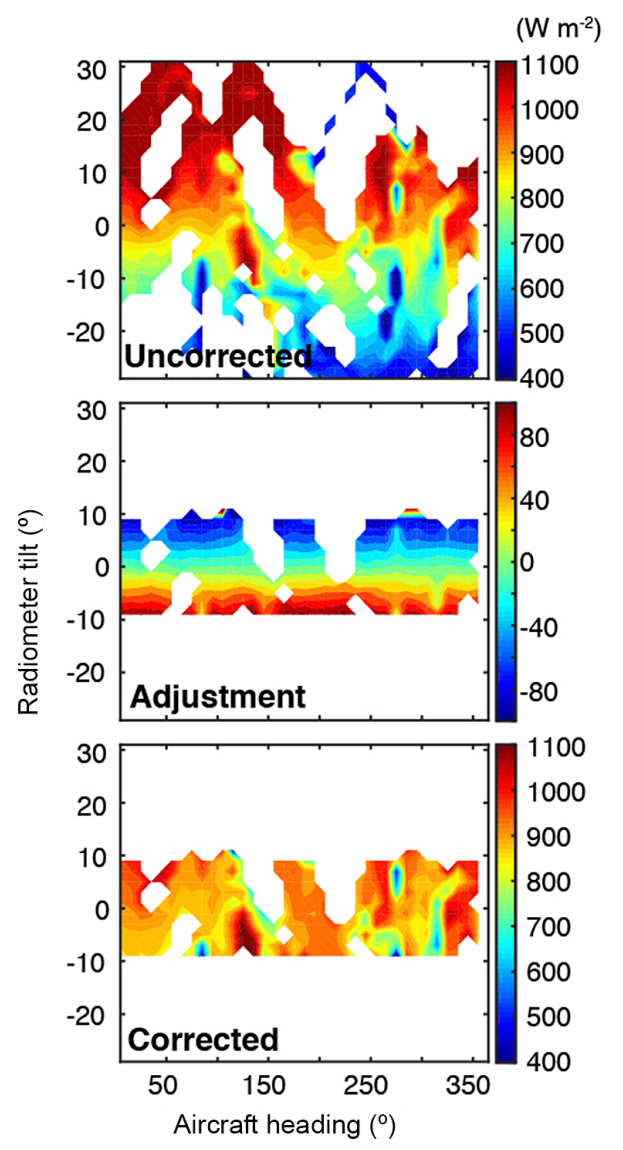

Figure 9. Downwelling shortwave irradiance $\left(\mathrm{W} \mathrm{m}^{-1}\right)$ from the two flights completed with the SPN1s. The top figure shows the mean, uncorrected irradiance detected across a variety of aircraft headings and tilt angles. The center figure illustrates the amount of the adjustment as dictated by the correction algorithm, and the bottom figure shows the final corrected values. Note that tilt angles greater than $10^{\circ}$ in magnitude are not corrected.

In addition to the computed irradiances, we can use these measurements to measure the surface albedo. As discussed previously, 3 April initially featured a patchy snow-covered ground surface, but warm temperatures helped to rapidly melt the snow. This is very apparent in the albedo measurements (Fig. 11), with the flight 1 albedo values generally varying between 0.25 and 0.35 , with some higher and lower values. In contrast, the albedo measurements from the later flight 4, which occurred after the snow had completely melted, are all generally in the 0.2 range, with the exception of the portion of the flight over the light-colored concrete runway, where values were closer to 0.27 . Gaps in the albedo measurement are found in places where the autopilot was transitioning between waypoints with bank angles in excess of $10^{\circ}$ (generally at the corners of the racetrack pattern).

Finally, POPS was operated on three of the four flights completed on 3 April 2015, with the instrument disabled during flight 3 . Particle size distributions indicating number

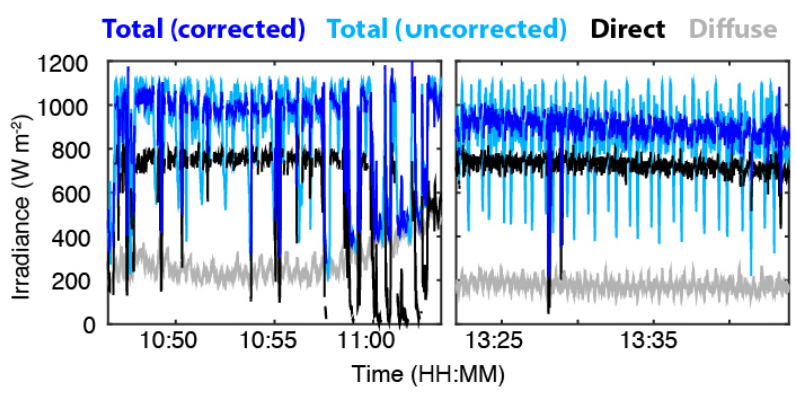

Figure 10. Time series of the SPN1 measured downwelling broadband irradiance for the two flights on which these sensors were flown. Included are the raw (uncorrected) total values in light blue, the tilt-corrected total values in darker blue, as well as the direct (black) and diffuse (grey) contributions to the measured signal.

(top), surface area (middle) and volume (bottom) are shown in Fig. 12 for the three remaining flights. As may be expected, there was very little change to the total size distributions obtained over the $5 \mathrm{~h}$ period between the surface and $100 \mathrm{~m}$ altitude. There does appear to be a slight redistribution of particles on the small end of the size spectrum (between 200 and $300 \mathrm{~nm}$ ) from the first two flights to the last flight. Note that sharp features in the size distribution like the dip at $\sim 300 \mathrm{~nm}$ or the peak at $350 \mathrm{~nm}$ are caused by a mismatch of the index of refraction of the environmental aerosol particles and the particles used to calibrate POPS (Gao et al., 2016).

\section{Summary and outlook}

In this paper, the RECUV Pilatus unmanned research aircraft is presented. This system was developed specifically for the measurement of atmospheric radiation, atmospheric aerosol particle size distribution, and atmospheric thermodynamic state. To do so, the aircraft is equipped with up- and downward looking Delta-T SPN1 broadband pyranometers, up- and downward looking Kipp and Zonen CGR4 pyrgeometers, the NOAA-designed Printed Optical Particle Spectrometer (POPS) and a housing to carry an NCAR PTH module. The PTH module and POPS instrument are flown at all times, and the radiation payload is configurable to measure up- and downwelling shortwave or longwave, but not both together due to size and weight restrictions. In order to correct the measured downwelling shortwave irradiance for variability resulting from aircraft pitch and roll, the Pilatus is also equipped with a VectorNav high grade INS. In order to characterize any angular offset between the VectorNav and the SPN1s, the two sensors were co-mounted on a single plate. This configuration was calibrated by mounting the system to the top of a car and driving a predefined path on a cloudless, dry day.

Measurements from a series of test flights flown on 3 April 2015 are presented. The first and last flights of that day fea- 


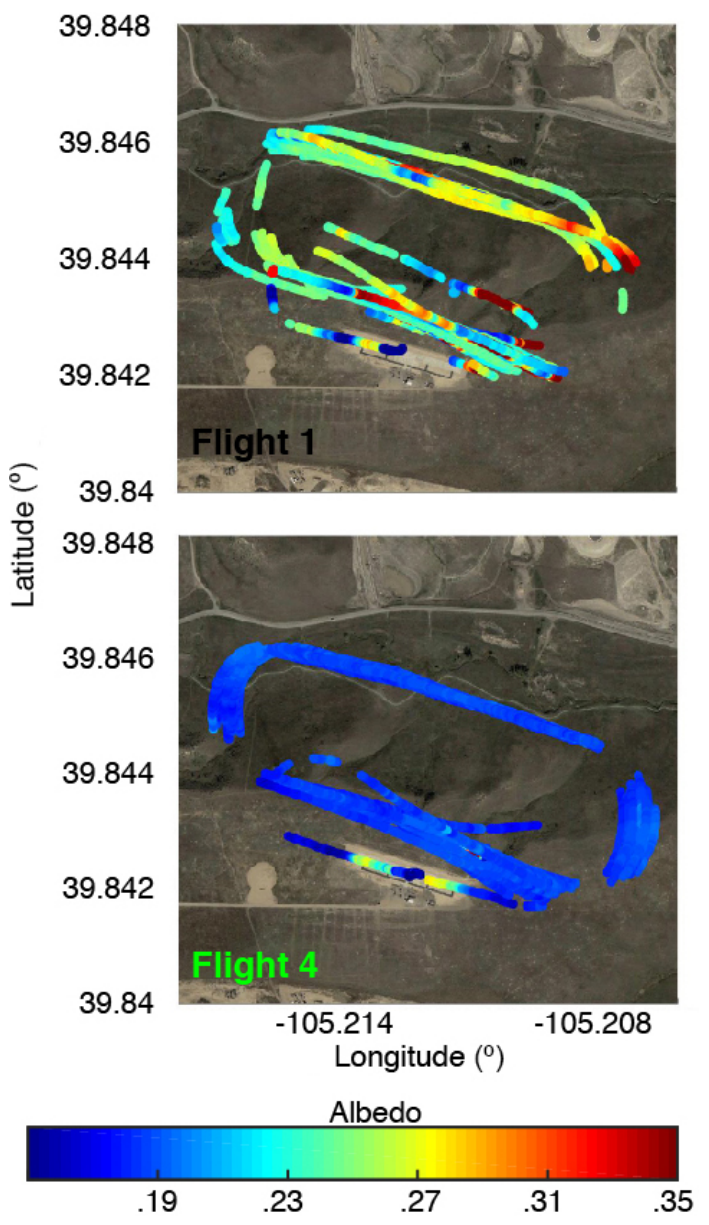

Figure 11. Surface albedo, as derived from the onboard SPN1 instruments. Note that the first flight was completed when the surface still had a significant amount of snow present, while the second flight was completed when most of the snow had melted. Points with tilt angles exceeding $10^{\circ}$ were excluded from this figure.

tured the SPN1 (shortwave) payload, while the second and third flights featured the CGR-4 (longwave) payload. All four flights also included the PTH module and POPS, although POPS data was not collected during the third flight. These initial flights clearly illustrated the sensitivity of both the short- and longwave measurements to aircraft orientation, with a combination of partial cloud cover and rolling terrain resulting in regular oscillations in both components. Such oscillations would likely be largely avoided when flying extended level legs, as planned for future deployments in regions where airspace is less restricted than at our test site.

The first extended field deployment of this system is planned for early April 2016. At this time, the aircraft and its crew are scheduled to deploy to Oliktok Point, Alaska to measure aerosol and radiation properties associated with the end of the Arctic haze season. Oliktok Point provides a unique operating environment due to the presence of US DOE-controlled restricted airspace (area R-2204). This area

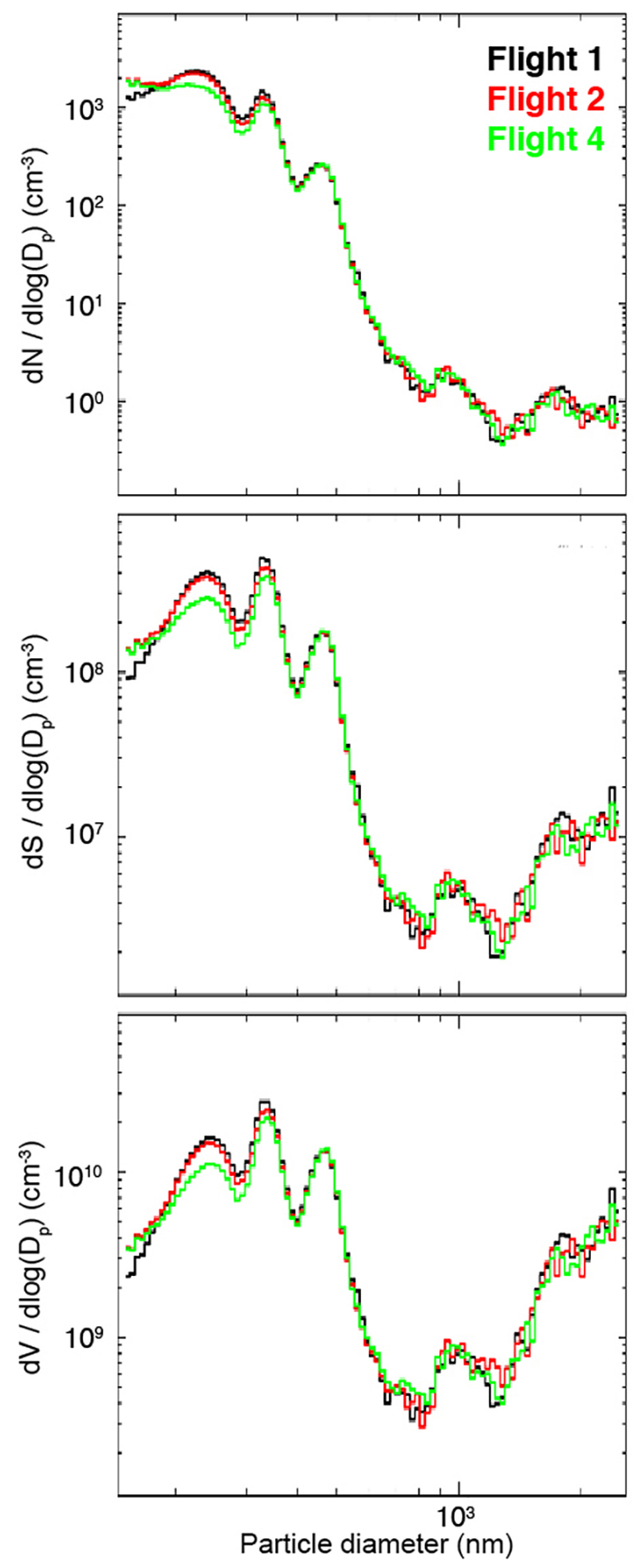

Figure 12. Particle size distributions represented as the number of particles (top), the surface area of particles (middle) and the volume of particles (bottom) for the three test flights during which POPS was operating on 3 April 2015.

of restricted airspace is made up of two cylinders with a diameter of 4 nautical miles, the first of which extends from the surface to $457 \mathrm{~m}(1500 \mathrm{ft})$ above sea level and the second of which extends between $457 \mathrm{~m}(1500 \mathrm{ft})$ to $2134 \mathrm{~m}$ (7000 ft). Access to this airspace allows for the execution of the extended level legs desired for radiation measurements, as well as increased vertical space to acquire profiles of aerosols, ra- 
diation and thermodynamics over the lowest kilometer of the Arctic atmosphere.

The general concept of making radiation, aerosol and thermodynamic measurements from platforms such as the Pilatus holds a lot of promise. Favorable comparison of Pilatus measurements with those obtained from other sources gives confidence in the ability of this aircraft to obtain highquality observations. Future development of a new airframe with similar instrumentation and payload capabilities would likely result in a more efficient system, and allow flight duration to increase. Extended flight time will allow aircraft such as the Pilatus to explore higher altitudes and greater spatial scales. For the time being, the upcoming Alaska deployment represents an opportunity to evaluate Arctic Haze in a new manner, with emphasis on the lowest kilometer of the atmosphere. Using this platform, we hope to be able to capture information on the vertical variability of aerosol size distribution, as well as the radiative impact of this polluted layer. We expect to time the campaign in a way where we will be able to measure the transition from polluted to cleaner conditions along the North Slope of Alaska during this deployment. In the near future, we will work to further improve the quality of the measurements being made by attempting to further minimize noise, particularly in the radiation measurements. Over a longer time frame, we hope to deploy the aircraft for future missions in the Arctic as well as at lower latitudes to observe processes related to aerosols, radiation and thermodynamics.

Acknowledgements. Funding for the development and upcoming deployment of the aircraft to Alaska is provided by the United States Department of Energy (DOE) Atmospheric System Research (ASR) and Atmospheric Radiation Measurement (ARM) programs under grant DE-SC0011459. Instrumentation for operations is on loan from the Pacific Northwest National Laboratory (CGR4s and SPN1s), the National Center for Atmospheric Research (PTH module), the National Oceanographic and Atmospheric Administration (POPS) and University of Colorado Research and Engineering Center for Unmanned Vehicles (VectorNav). We wish to thank Douglas Weibel and Tevis Nichols for their contributions to operation of the aircraft during test flights and Jack Elston for his input into the initial discussions for this project.

Edited by: M. Kulie

\section{References}

Atmospheric System Research (ASR) Science and Program Plan, US Department of Energy, Office of Science, 2010.

Altstädter, B., Platis, A., Wehner, B., Scholtz, A., Wildmann, N., Hermann, M., Käthner, R., Baars, H., Bange, J., and Lampert, A.: ALADINA - an unmanned research aircraft for observing vertical and horizontal distributions of ultrafine particles within the atmospheric boundary layer, Atmos. Meas. Tech., 8, 16271639, doi:10.5194/amt-8-1627-2015, 2015.
Anderson, T., Charlson, R., Schwartz, S., Knutti, R., Boucher, O., Rodhe, H., and Heintzenberg, J.: Climate forcing by aerosols - a hazy picture, Science, 300, 1103-1104, 2003.

Baron, P. and Willeke, K.: Aerosol Measurement: Principles, Techniques and Applications, John Wiley and Sons, New York, NY, 2001.

Bates, T. S., Quinn, P. K., Johnson, J. E., Corless, A., Brechtel, F. J., Stalin, S. E., Meinig, C., and Burkhart, J. F.: Measurements of atmospheric aerosol vertical distributions above Svalbard, Norway, using unmanned aerial systems (UAS), Atmos. Meas. Tech., 6, 2115-2120, doi:10.5194/amt-6-2115-2013, 2013.

Brock, C. A., Cozic, J., Bahreini, R., Froyd, K. D., Middlebrook, A. M., McComiskey, A., Brioude, J., Cooper, O. R., Stohl, A., Aikin, K. C., de Gouw, J. A., Fahey, D. W., Ferrare, R. A., Gao, R.-S., Gore, W., Holloway, J. S., Hübler, G., Jefferson, A., Lack, D. A., Lance, S., Moore, R. H., Murphy, D. M., Nenes, A., Novelli, P. C., Nowak, J. B., Ogren, J. A., Peischl, J., Pierce, R. B., Pilewskie, P., Quinn, P. K., Ryerson, T. B., Schmidt, K. S., Schwarz, J. P., Sodemann, H., Spackman, J. R., Stark, H., Thomson, D. S., Thornberry, T., Veres, P., Watts, L. A., Warneke, C., and Wollny, A. G.: Characteristics, sources, and transport of aerosols measured in spring 2008 during the aerosol, radiation, and cloud processes affecting Arctic Climate (ARCPAC) Project, Atmos. Chem. Phys., 11, 2423-2453, doi:10.5194/acp-11-24232011, 2011.

Cassano, J., Maslanik, J., Zappa, C., Gordon, A., Cullather, R., and Knuth, S.: Observations of Antarctic polynya with unmanned aircraft systems, EOS, 91, 245-246, doi:10.1029/2010EO280001, 2010.

Corrigan, C. E., Roberts, G. C., Ramana, M. V., Kim, D., and Ramanathan, V.: Capturing vertical profiles of aerosols and black carbon over the Indian Ocean using autonomous unmanned aerial vehicles, Atmos. Chem. Phys., 8, 737-747, doi:10.5194/acp-8-737-2008, 2008.

Curry, J., Maslanik, J., Holland, G., and Pinto, J.: Applications of Aerosondes in the Arctic, B. Am. Meteorol. Soc., 85, 18551861, doi:10.1175/BAMS-85-12-1855, 2004.

Elston, J., Roadman, J., Stachura, M., Argrow, B., Houston, A., and Frew, E.: The tempest unmnaned aircraft system for in situ observations of tornadic supercells: Design and VORTEX2 flight results, J. Field Robot., 28, 461-483, doi:10.1002/rob.20394, 2011.

Gao, R.-S., Telg, H., McLaughlin, R., Ciciora, S., Watts, L., Richardson, M., Schwarz, J., Perring, A., Thornberry, T., Rollins, A., Markovic, M., Bates, T., Johnson, J., and Fahey, D.: A light-weight, high-sensitivity particle spectrometer for PM2.5 aerosol measurements, Aerosol Sci. Technol., 50, 88-99, doi:10.1080/02786826.2015.1131809, 2016.

Houston, A., Argrow, B., Elston, J., Lahowetz, J., Frew, E., and Kennedy, P.: The collaborative Colorado-Nebraska unmanned aircraft system experiment, B. Am. Meteorol. Soc., 93, 39-54, doi:10.1175/2011BAMS3073.1, 2012.

Intrieri, J. M., de Boer, G., Shupe, M. D., Spackman, J. R., Wang, J., Neiman, P. J., Wick, G. A., Hock, T. F., and Hood, R. E.: Global Hawk dropsonde observations of the Arctic atmosphere obtained during the Winter Storms and Pacific Atmospheric Rivers (WISPAR) field campaign, Atmos. Meas. Tech., 7, 39173926, doi:10.5194/amt-7-3917-2014, 2014.

Jacob, D. J., Crawford, J. H., Maring, H., Clarke, A. D., Dibb, J. E., Emmons, L. K., Ferrare, R. A., Hostetler, C. A., Russell, P. B., 
Singh, H. B., Thompson, A. M., Shaw, G. E., McCauley, E., Pederson, J. R., and Fisher, J. A.: The Arctic Research of the Composition of the Troposphere from Aircraft and Satellites (ARCTAS) mission: design, execution, and first results, Atmos. Chem. Phys., 10, 5191-5212, doi:10.5194/acp-10-5191-2010, 2010.

Jensen, E., Diskin, G., Lawson, R., Lance, S., Bui, T., Hlavka, D., McGill, M., Pfister, L., Toon, O., and Gao, R.-S.: Ice nucleation and dehydration in the tropical tropopause layer, P. Natl. Acad. Sci. USA, 110, 2041-2046, doi:10.1073/pnas.1217104110, 2013.

Lawrence, D. and Balsley, B.: High-resolution atmospheric sensing of multiple atmospheric variables using the DataHawk small airborne mesurement system, J. Atmos. Ocean. Technol., 30, 2352 2366, doi:10.1175/JTECH-D-12-00089.1, 2013.

Lin, P.-H.: The first succesful typhoon eyewall-penetration reconnaissance flight mission conducted by the unmmaned aerial vehicle, aerosonde, B. Am. Meteorol. Soc., 87, 1481-1483, doi:10.1175/BAMS-87-11-1481, 2006.

Long, C., Bucholtz, A., Jonsson, H., Schmid, B., Vogelmann, A., and Wood, J.: A method of correcting for tilt from horizontal in downwelling shortwave irradiance measurements on moving platforms, Open Atmos. Sci. J., 4, 78-87, doi:10.2174/1874282301004010078, 2010.

Martin, S., Bange, J., and Beyrich, F.: Meteorological profiling of the lower troposphere using the research UAV "M2AV Carolo", Atmos. Meas. Tech., 4, 705-716, doi:10.5194/amt-4-705-2011, 2011.

McFarquhar, G., Ghan, S., Verlinde, J., Korolev, A., Strapp, J., Schmid, B., Tomlinson, J., Wolde, M., Brooks, S., Cziczo, D., Dubey, M., Fan, J., Flynn, C., Gultepe, I., Hubbe, J., Gilles, M., Laskin, A., Lawson, R., Leaitch, W., Liu, P., Liu, X., Lubin, D., Mazzoleni, C., Macdonald, A.-M., Moffet, R., Morrison, H., Ovchinikov, M., Shupe, M., Turner, D., Xie, S., Zelenyuk, A., Bae, K., Freer, M., and Glen, A.: Indirect and Semi-Direct aerosol campaign: The impact of Arctic aerosols on clouds, B. Am. Meteorol. Soc., 92, 183-201, 2011.

Persson, P., Fairall, C., Andreas, E., Guest, P., and Perovich, D.: Measurements near the atmospheric surface flux group tower at SHEBA: Near-surface conditions and surface energy budget, J. Geophys. Res., 107, 8045, doi:10.1029/2000JC000705, 2002.
Platis, A., Altstädter, B., Wehner, B., Wildmann, N., Lampert, A., Hermann, M., Birmili, W., and Bange, J.: An observational case study on the influence of atmospheric boundary-layer dynamics on the new particle formation, Bound.-Lay. Meteorol., 158, 1-26, doi:10.1007/s10546-015-0084-y, 2015.

Raatz, W. and Shaw, G.: Long-range tropospheric transport of pollution aerosols in the Alaskan Arctic, J. Clim. Appl. Meteor., 23, 1052-1064, 1984.

Rahn, K.: Relative importance of North America and Eurasia as sources of Arctic aerosol, Atmos. Environ., 15, 1447-1455, doi:10.1016/0004-6981(81)90351-6, 1981.

Ramana, M., Ramanathan, V., Kim, D., Roberts, G., and Corrigan, C.: Albedo, atmospheric solar absorption and heating rate measurements with stacked UAVs, Q. J. Roy. Meteor. Soc., 133, 1913-1931, doi:10.1002/qj.172, 2007.

Reuder, J., Jonassen, M., and Ólafsson, H.: The small unmanned meteorological observer SUMO: Recent developments and applications of a micro-UAS for atmospheric boundary layer research, Acta Geophys., 60, 1454-1473, doi:10.2478/s11600012-0042-8, 2012.

Stephens, G., Ellingson, R., Vitko, J., Bolton, W., Tooman, T., Valero, F., Minnis, P., Pilewskie, P., Phipps, G., Sekelsky, S., Carswell, J., Miller, S., Benedetti, A., McCoy, R., McCoy, R., Lederbuhr, A., and Bambha, R.: The Department of Energy's Atmospheric Radiation Measurement (ARM) Unmanned Aerospace Vehicle (UAV) Program, B. Am. Meteorol. Soc., 81, 2915-2938, 2000.

Valero, F., Pope, S., Elingson, R., Strawa, A., and Vitko, J.: Determination of clear-sky radiative flux profiles, heating rates and optical depths using unmanned aerospace vehicles as a platform, J. Atmos. Ocean. Technol., 13, 1024-1030, 1996.

van den Kroonenberg, A., Martin, S., Beyrich, F., and Bange, J.: Spatially-averaged temperature structure parameter over a heterogeneous surface measured by an unmanned aerial vehicle, Bound.-Lay. Meteorol., 142, 55-77, doi:10.1007/s10546-0119662-9, 2012. 